\title{
Intertextuality and failed taboo humour in advertising
}

\author{
Margherita Dore \\ University of Rome "La Sapienza", Italy \\ margherita.dore@uniroma1.it
}

\begin{abstract}
Humour is often exploited in advertising to enhance the positive image of a brand or corporate company, as well as to promote products or services. Advertisers seek the involvement of the audience via covert or overt references that, in their opinion, may trigger humour and, hypothetically, result in a positive customer response. However, using intertextual humour in advertising can sometimes be risky because, even though the ideal interlocutor is supposed to be familiar with the humorous reference the author alludes to, the latter can never be certain of whether it will be favourably received. The matter is further complicated if the advert relies on references that play on taboo or transgressive topics, which some may find humorous while others will consider distasteful. After all, humour is a phenomenon that varies according to individual cultures and historical time, as well as in terms of how it is perceived and whether it is appreciated. In this context, this study focuses on the use of intertextual taboo humour in adverts and campaigns that exploit both verbal and non-verbal texts. It particularly explores the reasons for the target clientele's reaction, which has had a boomerang effect on the brand and company itself. The suggested hypothesis is that the simultaneous exploitation of verbal and non-verbal intertextual references (consciously or unconsciously) activates multiple targets and scripts that cause the intended humour to fail in its scope.
\end{abstract}

Keywords: hyperdetermined humour, intertextuality, advertising, (multi)national corporation.

\section{Introduction}

Today's global market often features advertising campaigns that have been designed to promote a unified image of a brand (e.g. the worldwide campaigns by Coca-Cola). This helps multinational corporations to cut advertising costs for local markets. However, cultural barriers and language-related issues can make this approach impracticable and opting for an unlocalised campaign may be detrimental to the message in the advert and the brand itself (Biswas et al. 1992). That said, even localised campaigns offer no guarantee of success. Besides, the very idea of "localised" advertising campaigns nowadays needs to be challenged, 
since any advert designed for a given target culture can easily be viewed, shared and commented over the internet.

Over the years, humour in advertising has attracted the attention of many scholars (Bernstein 1974; Speck 1991; MacInnis et al. 1991; Catanescu \& Tom 2001; Forceville 2007; Beard 2008; Freitas 2008, 2016; Hatzithomas et al. 2016, just to name a few). They have explored this phenomenon, confirming its importance in marketing and focussing in particular on its effectiveness in increasing the processing of information, as it stimulates attention (MacInnis et al. 1991). Furthermore, it has been argued that adverts which attempt to appeal to their prospective (national or international) clientele's sense of humour, while promoting products and services, should generally have a positive effect on the perception of the brand or corporate company that provides them (Flaherty et al. 2004: 26).

Generally speaking, people tend to prefer or expect "good humour" and taboo topics are socially sanctioned because they are more likely to embarrass than amuse their audience (Bell 2015: 3-4). Themes such as age, gender etc. are normally considered taboo because they may relate respectively to death and sex. In her book-length study on taboo ads, Freitas (2008: 39) explains that taboo "corresponds to a number of restrictions that regulate some areas of social life, and that demand avoidance behaviour because (1) the situation is dangerous for the individual and (2) that danger could contaminate others". In other words, we tend to abide by behavioural norms to avoid disrupting the status quo. However, challenging and/or breaking such an unspoken rule can become a witty way to trigger attention and persuade, especially in advertising. In Sabri's (2012: 408) definition, taboo advertising

uses images, words, or situations to broach a topic that has proscribed status for a proportion of a target audience, such as homosexuality, transvestism, bestiality, racism, or capital punishment. It can shock or offend by transgressing internalized behavioral or conversational norms or by triggering emotionally ambivalent responses, such as simultaneous excitement and guilt.

Stimuli based on taboo topics are associated with properties such as novelty, incongruity and surprise, which have the ability to evoke arousal, an antecedent condition for attention (Sabri 2012: 409).

However, not all taboo advertising is humorous and not all humour in advertising hinges on taboo themes. When marketers opt for taboo humour in advertising, Freitas (2008: 111) warns that: "[t]he final purpose would always be to achieve a delicate balance between the amount of information conveyed and the ability to engage and maintain the viewer's attention through the use of humour". In order to achieve this delicate balance, advertisers make use of more or less covert intertextual taboo references, probably because "obscenity, by being intertextually linked to apparently inoffensive humour, becomes acceptable" (Hill 2005: 116). It is important to note that, if the receiver is unable to retrieve the reference from their background knowledge, communication is likely to freeze (until the reference is explained) or stop completely (if an explanation is not given, requested or searched for; cf. Norrick 1993: 70; Werner 2004: 4). As Tsakona (2018: 1) shrewdly argues, intertextuality has the power to create insiders and outsiders, thus becoming a sign of superiority. Correctly processing the reference may become a symbol of "cultural prestige" (Ermida 2008: 197; see also Hill 2005 on the sense of superiority and language mockery via intertextuality). Intertextual humour makes this display of superiority even more obvious. Implicit or explicit references can be important aids to signalling humour (Montgomery et al. 2007: 156-161; Ermida 2008: 164). Hence, getting the reference also means understanding its underlying humorous message, which produces a "conspiratorial pleasure" among those "in the know" (Kuipers 2009: 229; cf. also Freitas 2008: 149). 
That said, even when the receiver is able to access the humorous reference, this does not guarantee its acceptance. As Hale (2018: 523) rightly observes, "the person who can attract interlocutors' positive attention with a humorous and intertextual reference can garner attention and capital in quite significant measure", yet "[ $t$ ]he textual author cannot be certain, even if their interlocutor is familiar with the original humorous text, that a subsequent reference to the original, in a new context, will be favourably received" (emphasis in original). Furthermore, Hale explains: "Many people can perceive and process the intertextuality in humour, but they don't necessarily find it funny" (Hale 2018: 523; cf. also Gulas \& Weinberger 2016: 187 for similar considerations). It is equally true that some people may get the intertextual joke but avoid expressing their appreciation due to social and cultural norms. As discussed above, this happens particularly when taboo topics are involved.

As mentioned earlier, choosing taboo themes in advertising is indeed risky business and the chances of the humour failing are high. This is due to the fact that there is a threshold beyond which taboo tactics in advertising become counterproductive (Sabri 2012: 418). This paper is therefore devoted to the investigation of some instances of taboo humour in advertising that have failed dramatically. I will examine how intertextual references to transgressive themes are conveyed via the simultaneous exploitation of verbal and non-verbal signs (i.e. visual, and aural for TV commercials) to promote a product or a service. The multimodal and simultaneous manifestation of taboo intertextualities proves to be the primary cause of the failure of these ads. For the data analysis, I will draw on Attardo's $(1994,2001)$ notions of Script Opposition and Target and the idea of hyperdetermined humour. These tools can reveal what oppositions and targets the intertextual taboo references in the ad activate. Moreover, they can explain why these ads have sparked strong reactions among many of their receivers.

\section{2. (Taboo) humour in advertising}

Adverts are created by marketers in order to reach a prospective pool of local, national and/or international customers. From a general point of view, an ad can be described as a message conceived by an advertiser (or advertising company) that is sent to its target receivers. Simpson et al. (2019: 36) label tickle adverts those which appeal to humour, emotions and mood. Freitas (2008: 8-13) further categorises ads into print ads (that appear in magazines), outdoor adverts (billboards, banners, etc.), and TV commercials (see also Forceville 2007: 18). However, nowadays all three types of ads can easily be found on the internet and social media, such as Instagram, Facebook etc. Hence, their categorisation mainly rests on the fact that print and outdoor ads involve a combination of linguistic and non-linguistic features (words and images) whereas TV commercials exploit verbal, visual, kinetic and aural (i.e. music and sound) modes of communication. Hence, the analysis of the data under scrutiny will specifically focus on instances of failed taboo tickle adverts and commercials.

Before proceeding, it is important to understand the reasons why marketers use humour (and taboo) in advertising. In his book-length study, Berger (2015 [2000]: 18) explains that advertisers in the past were afraid of humour, probably because it may challenge interpersonal and social relations (see also Norrick 1993: 105-106) or because of its potential offensiveness, which may be either inadvertent or intentional (Beard 2008). Yet marketers have also realised that humour helps sell because it can create what he calls the halo effect, meaning "a feeling of well-being that becomes attached to the products being advertised" (Berger 2015 [2000]): 1819). Indeed, general findings show that receivers' attitude towards an advertisement is more positive when it includes humour (Sabri 2012: 418). However, such a trade-off effect is not necessarily guaranteed, especially if the humour in the ad is not relevant to the message 
conveyed (MacInnis et al. 1991: 37) or is potentially disturbing. In such cases, using humour produces the so-called vampire effect, sucking attention away from the product or message advertised (Catanescu \& Tom 2001: 92).

As Freitas (2008: 106) rightly points out, if we want to study (taboo) humour in advertising, we need to consider factors such as the kind of product or service being advertised, the audiences it is aimed at, the media used to convey it, the type of humorous message in the ad, as wells as the various contextual and situational factors that can interfere with the way a humorous advertising message is received at a given time. For their part, Gulas \& Weinberger (2006: 51-52) also include demographic (age, gender, etc.), psychographic (cognitive engagement), self-monitoring (context and beliefs) and ideological (political stance) factors, along with one's personal sense of humour. Truly enough, humour perception and appreciation are likely to depend on one's personal disposition and/or contingent factors. For example, Hatzithomas et al. (2016) have shown the influence of economic conditions on the appreciation of humour in advertising. In addition, what may determine the (in)appropriateness of humour is often due to the norms established in a given socio-cultural setting (Attardo 1994: 319; cf. also Chovanec \& Tsakona 2018: 5-6 for similar considerations).

Humour based on taboo themes is very difficult to handle. Yet although taboos can evoke strong and contradictory emotions, advertisers usually know how to play on them to their advantage (Freitas 2008: 198). In order to do this, "an apparently innocuous linguistic message can be twisted or contradicted by the non-linguistic elements presented - or viceversa, since we are using two different means of expression" (Freitas 2008: 4; my emphasis). For example, in the 2006 Italian Amica Chips (or crisps in British English) TV commercial, the supposedly innocuous non-linguistic (visual and aural) message is twisted by the ambiguous verbal text, which contains a taboo reference. This TV commercial stars the internationally renowned and now retired porn actor Rocco Siffredi. While Boney M's song "Daddy Cool" plays in the background, Siffredi is pictured at a private pool party eating potato chips while surrounded by many young, beautiful women. He utters sentences such as "I've tried many chips in my life", "I've tried them all: German, English, Dutch... But none of them are like this one". ${ }^{1}$ The verbal taboo reference plays on the Italian word patata ('potato') and, by extension, patatina ('chips'), used to refer to female genitalia. All the intertwining layers of meaning and references (Siffredi's lines, images and soundtrack) contribute to the ambiguous reading of the commercial and its taboo interpretation. Some people contended that the ad was offensive to women (an instance of "sexist advertising" that demeans or objectifies women; Gulas \& Weinberger 2006: 177), while the company defended the light-hearted attitude of the commercial. Many people, including women, aligned with the company's view. ${ }^{2}$ Remarking the intended funniness of a potentially offensive ad is a commonly used defence strategy among advertisers (Gulas \& Weinberger 2016: 187). Interestingly, some people also complained that this commercial was potentially disturbing for children, but the counterargument was that children are unlikely to get the double entendre the intertextual reference alludes to (although some parents do use patatina as a euphemism for female genitalia when talking to their children). Furthermore, children are unlikely to know who Rocco Siffredi is or, even if they do, are probably unaware of the type of films he starred in. Consequently, the commercial continued to be broadcast and other commercials playing on the same idea and starring Siffredi were subsequently produced, even as recently as 2019.

\footnotetext{
1 The Amica Chips and Rocco Siffredi ad can be retrieved at: https://www.youtube.com/watch? $\mathrm{v}=\mathrm{oUn} 4$ 6huLOM (accessed: 20.04.2020).

2 The following thread (in Italian) reports a (male) client's complaint to Amica Chips, the company's answer, and some ironic comments on the man's attitude, which is defined as sanctimonious and outdated, https://www.fremen.it/vbulletin/archive/index.php/t-3827.html (accessed: 20.04.2020).
} 
The potential offensiveness of taboo ads is surely one of their inherent characteristics. The success of the Amica Chips example is probably due to the fact that the taboo references have kept within the boundaries of what is considered acceptable (cf. Freitas 2016: 182). Acceptability clearly plays an essential role in humorous taboo advertising. In their extensive study of humour in advertising, Gulas \& Weinberger (2006) analysed a series of ads based on themes such as race and sex, and found that, even when the receivers recognised that the advert was meant to be humorous, they nevertheless found it offensive because of the topic they were playing on (Gulas \& Weinberger 2006: 187; see also Dore 2018 on failed attempts to poke fun at both men and women using gender-based stereotypes in advertising). The concept of offensiveness is explained via superiority theories that postulate that humour is based on "winners" and "losers". The latter are associated with groups via gender, age, ethnicity, etc. and those who relate to one or more of these groups are likely to get offended by the humour that targets them (Gulas \& Weinberger 2016: 171). As we will see later, even people who do not directly associate themselves with the targeted group may still get offended and vice versa.

Acceptance, offensiveness and (in)appropriateness in taboo humour advertising are very relative and subjective concepts. The famous and much debated 2008 Absolute Vodka advert is a good example in this sense. It showed a 19th-century map of Mexico with its borders extending further north to include part of the US territory. Since the ad was aimed at the Mexican audience, it appeared successful in terms of target clientele and contextual and situational factors. What the advertisers may not have envisaged was that this ad could be picked up by the US media, which roundly criticised this campaign and encouraged US citizens to boycott Absolute Vodka and its products. Eventually, the company was forced to withdraw the ad and publicly apologise (Reuters 2008). For Pernod Ricard, the French group that owns Absolute Vodka, such a drastic action is a clear attempt to ward off business losses in markets that are likely to ensure high returns. The US citizens' vehement reaction and the company's subsequent moves prove that even apparently innocuous intertextualities can threaten status (Freitas 2008: 198) and become detrimental to the product or brand that attempts to exploit them for humorous purposes.

\section{Intertextuality in/and humour}

An extensive discussion of intertextuality is clearly beyond the scope and objectives of this paper (see Allen's 2000 book-length overview of intertextuality). It will suffice to say that Kristeva (1980) first developed this concept by combining Saussure's (1974) and Bakhtin's (and Volosinov's 1986) ideas: the former postulated the essential connection between meaning and text, whereas the latter explored the use of language in specific contexts (Allen 2000: 2-3). Kristeva's (1980) famous definition of intertextuality reads as follows: "any text is constructed of a mosaic of quotations; any text is the absorption and transformation of another" (Kristeva 1980: 66). Norrick's (1989) seminal work on intertextuality in humour has further expanded this notion by claiming that "[i]ntertextuality occurs any time one text suggests or requires reference to some other identifiable text or stretch of discourse, spoken or written". Tsakona (2018) identifies different categories of intertextual references: (1) references to sociopolitical and cultural contexts, events, and stereotypes; and (2) references to fixed expressions (e.g. proverbs, idioms), linguistic resources (e.g. registers or other languages) or other texts and genres (whether literary or not; ibid. 5). This broader view is also accepted here because, as I will show later, most intertextual humour in my data is based on stereotypes as well as idiomatic expressions. 
Scholars in many fields of inquiry have investigated intertextuality as a covert or overt means to convey humour (e.g. Hlynka \& Knupfer 1997; Werner 2004; Hill 2005; Dore 2010, 2019; Boxman-Sabtai \& Shifman 2014). Within Humour Studies, "[t]he close relationship between humor and intertextuality is not news" (Tsakona 2018: 12). Many humour scholars have frequently debated the inherent relation between humour and intertextuality (Norrick 1989; Attardo 1994: 180; 2001: 61; Laineste \& Voolaid 2016). As Tsakona (2018: 3) explains, even the currently most applied and well-known theories on humour based on script ${ }^{3}$ overlapping and opposition rely on intertextuality, meaning Raskin's (1985) Script-based Semantic Theory of Humour (SSTH) and Attardo's (1994, 2001) General Theory of Verbal Humour (GTVH). I will concentrate particularly on the latter.

In a nutshell, GTVH entails six Knowledge Resources, including Script Opposition. They are conceived according to a hierarchical structure, at the top of which is Script Opposition. The Logical Mechanism is the Knowledge Resource that explains how the two scripts are brought together (i.e. through juxtaposition, figure-ground reversal). Situation describes the context (e.g. objects, participants, activities) while Target defines the butt of the joke. The Narrative Strategy is responsible for the organisation of the text (e.g. a dialogue, narrative, figure of speech) and Language contains the information regarding the verbalisation of the text (Attardo 1994: 222-226). According to Attardo (1997), the Incongruity-Resolution model developed in psychology can aptly explain the interpretative process of a humorous text and it can be usefully matched to the GTVH's script opposition and logical mechanism in the following way. The Incongruity-Resolution model involves two steps. At first, the receiver interprets the text according to the linguistic cues and the script they activate. Subsequently, the punchline forces the receiver to detect the "incongruity" and then reinterpret the linguistic cues in the text according to another script, which is in opposition to the one activated previously. This step is called the "resolution" phase. As per this model, script opposition is the parameter that reveals the incongruity, while the logical mechanism is the parameter that resolves it (Attardo 1997: 415). However, in order to detect the incongruity, the interlocutor or receiver of the text needs to retrieve the opposing or overlapping scripts from their background knowledge. Hence, the script opposition, or incongruity, requires a reference to previous (con)texts to be established (Tsakona 2018: 3), and this is why intertextuality "lies at the heart of humour" (Attardo 2001: 71).

Over the last 25 years, GTVH has been developed, and revised, to account for the humour in jokes, longer texts, even humour in texts other than verbal texts (e.g. Gérin 2013). In order to investigate humour that combines verbal and non-verbal text, Tsakona's (2009) has drawn on Attardo's (2001: 100-101) notion of the hyperdetermination of humour (which is textual if more than one source of humour is present at the same time or punctual if the same source of humour is simultaneously activated in different moments) to examine humour in a corpus of newspaper cartoons. Tsakona (2009: 1181) demonstrates how hyperdetermined humour is the result of the interaction between language and/or image. Since several Script Oppositions and hyperdeterminations can be detected in the same text, this may also explain why people react differently to the same cartoon (Tsakona 2009: 1184). In a similar vein, Manteli (2011: 253) has used hyperdetermination to explain how humour in a modern Greek theatre play is activated via the co-occurrence of opposed and incongruous textual, intertextual and performative (e.g. props, musical score) signs (Manteli 2011: 257, 261). These various sources activate different Script Oppositions and address several Targets. Via a number of examples, she demonstrates how the scriptwriters exploit these different multimodal codes to create a

\footnotetext{
${ }^{3}$ A script is defined as "a cognitive structure internalised by the speaker which provides the speaker with information on how things are done, organised, etc." (Attardo 1994: 199).
} 
humorous effect, which allows her to define them as instances of hyperdetermined humour (Manteli 2011: 261-263).

With these premises in mind, the concept of hyperdetermined humour is applied to the analysis of a small corpus of adverts that simultaneously exploit the verbal and visual signs (and aural signs in commercials) to stake out different Script Oppositions and Targets of ridicule via the taboo references they activate (see also Boxman-Shabtai \& Shifman 2014). One important point to bear in mind for the sake of the present discussion is that, according to Chovanec \& Tsakona (2018: 13), Target and Script Opposition are the two Knowledge Resources that can be seen as part of the sociocultural context of humour because the latter refers to the topics that can be suitably exploited for humorous purposes in a given cultural community, whereas the former refers to those that can be attacked via humour. When considering taboo humour in adverts, the linguistic and non-linguistic intertextualities can be said to yield different interpretations, but also activate diverging targets. For instance, the creators of the ad may have an intended reading of the text and target(s) that, even if taboo, are not considered offensive. Some receivers may align with such an interpretation while others may depart from it and find another, related target(s) (cf. Tsakona 2018: 3) that they disapprove of (cf. the Amica Chips example above), thus generating opposing reactions.

As mentioned above, taboo in advertising is often an effective and successful means of persuading and triggering humour, yet it can also fail to do so. Hence, this study attempts to understand the reason(s) why taboo references that, although they elicit a great deal of surprise connected to the processing of the intertextual references involved, do not result in a positive customer response regarding the product and the brand itself. Specifically, the focus is on "humorous" taboo intertextualities in adverts that have been perceived as "too transgressive", "off-limits" or "bad taste" (Hale 2018: 513). They have elicited negative emotions and feedback, leading many receivers to get actively involved, taking action against these ads and forcing them to be modified or withdrawn and corporations to issue official apologies.

\section{Data analysis}

This Section discusses a small corpus of ads. Far from making overgeneralised claims, it attempts to show how national and multinational corporations or organisations have tried to exploit taboo references to generate humour and interest among their prospective buyers but have utterly failed in their scope. As mentioned earlier, I will concentrate primarily on tickle adverts since they generally involve humour and are supposed to elicit people's curiosity and participation (Bernstein 1974). To this end, overt or covert allusions are investigated by looking at the underlying Script Opposition(s) and Target(s) they may activate.

This analysis expands on the work I have already carried out on the exploitation of controversial topics in advertising and the social and cultural implications this practice can have (Dore 2018). Here, I mostly concentrate on the processes at work in the perception of taboo and transgressive themes within ads, as such references are inherently linked to humour (Attardo 1994: 155-156; Hempelmann \& Miller 2017). Whether they are overtly intentional regarding the taboo message they convey or "accidentally" offensive is a matter of perception, but I share Hale's (2018: 511) view that " $\mathrm{t}]$ here is no such thing as an 'accidental' intertextuality". All the adverts discussed below are considered instances of failed taboo humour because they encountered the opposition of part of their receivers to the extent that some had to be withdrawn. In all the cases, the companies tried to defend why they had proposed the ad and some even had to apologise publicly. Moreover, they have been selected because they draw their references from stereotypes and/or idiomatic expressions, etc. (Tsakona 2018) that are combined with the visual (and aural) text. 
Examples (1) and (2) below deal with racial issues, which are generally considered taboo, particularly in advertising (Sabri 2012: 408). I will start by discussing a billboard ad that combines verbal and visual text. Then I will turn to a commercial which simultaneously exploits verbal, visual and aural text. Example (1) (see Figure 1) is a recent instance of an advertising campaign that was criticised for the underlying message it seemed to convey. In 2018, the Swedish company H\&M launched an online campaign for children's clothing that, among others, featured a black child wearing a hooded sweatshirt with the writing "coolest monkey in the jungle".

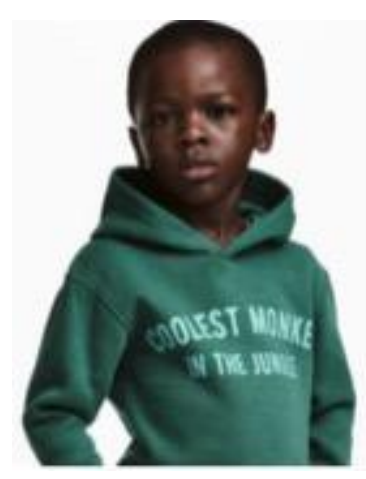

Figure 1. The criticised image of the H\&M children's clothing campaign. Source: https://www.nytimes.com/2018/01/08/business/hm-monkey.html

The writing on the sweatshirt seems to refer to the expression "cheeky monkey", which is a mild playful rebuke usually used with any mischievous children. In addition, the tongue-incheek statement "coolest monkey in the jungle" contains the superlative adjective "coolest", which conveys positive connotations. Hence, at a surface level, in GTVH terms, the verbal text activates Script Oppositions such as "good/bad" children and "appropriate/inappropriate behaviour". The Targets of this mild humorous reference are children who are naughty while well-behaved children are considered "cool".

Nevertheless, the advert was harshly criticised by many who claimed it was an indirect disparaging reference to black people. This alternative reading and new target are activated because of the matching of the verbal and visual texts, which become, if not incongruous, certainly inappropriate. The supposed hyperdetermined humour is conveyed by jointly exploiting verbal and non-verbal references that trigger many other Script Oppositions, such as "white/black people" or even "any other type of people/black people", and consequently "civilisation/jungle" and "human/non-human". Therefore, it enacted a sense of superiority by negatively associating "white" with "human" and "black" with "non-human". As a result, those receivers (whatever their racial background) who felt insulted by the ad probably extended the target not only to the child in the picture but to all black children and black people in general, or even to themselves because they are pictured as "losers". Even if all humans are said to descend from apes, the denial of humanness to black people is often present in our everyday life and the utterly racist trope that categorises them as monkeys is also very common in racist discourse (e.g. chants by racist fans at football matches or throwing banana skins at black players). If the child in the picture was Caucasian or Asian, probably many would still activate the monkey-human script but would not find it offensive, or perhaps only mildly so. It is the matching of the verbal text and the face of the black child that makes the potential humour in this ad fail. Incidentally, in today's norm-regulated and hyper-politically correct world, even those who may find this ad funny are likely to resist the temptation of reading the humour in this text, or at least will not do it publicly (cf. Tsakona 2018: 13). 
The company apologised profusely and ensured that the image was deleted from the internet and the garment removed from their stores. Interestingly, the image was said to have appeared in H\&M's online stores "in some European markets" (Stack 2018), which seems to suggest that the internet may still be conceived as somehow "local" and some of its content accessible to a limited number of people. This explanation would have been partly plausible if such content had been written in an "exotic" language, which is unlikely to be easily translated into other more popular languages (e.g. Hindi into Italian). However, choosing the English language (which is presently an internationally recognised lingua franca) and intertextually referring to one of its culturally salient expressions is clearly a globalising strategy that seems to contradict H\&M's claims.

Example (2) (in Figure 2) deals with three video commercials that were launched by the famous Italian designers Dolce and Gabbana on the Chinese market in 2018. ${ }^{4}$ They were harshly criticised for mocking Chinese culture. In these commercials, while traditional Chinese music plays in the background, an Asian model tries to eat respectively spaghetti, pizza and a huge cannolo (a traditional Sicilian dessert) with chopsticks, but she only manages to catch small bites of food. The model laughs at her own ineptitude, while the subtitles and voice-over in Chinese explain that Chinese and Italian eating habits are very different but Chinese people can still grasp a bit of Italian food and culture (Figure 2). Due to the public uproar, international media soon reported the incident and the Chinese subtitles were translated into English, thus fuelling further discontent.

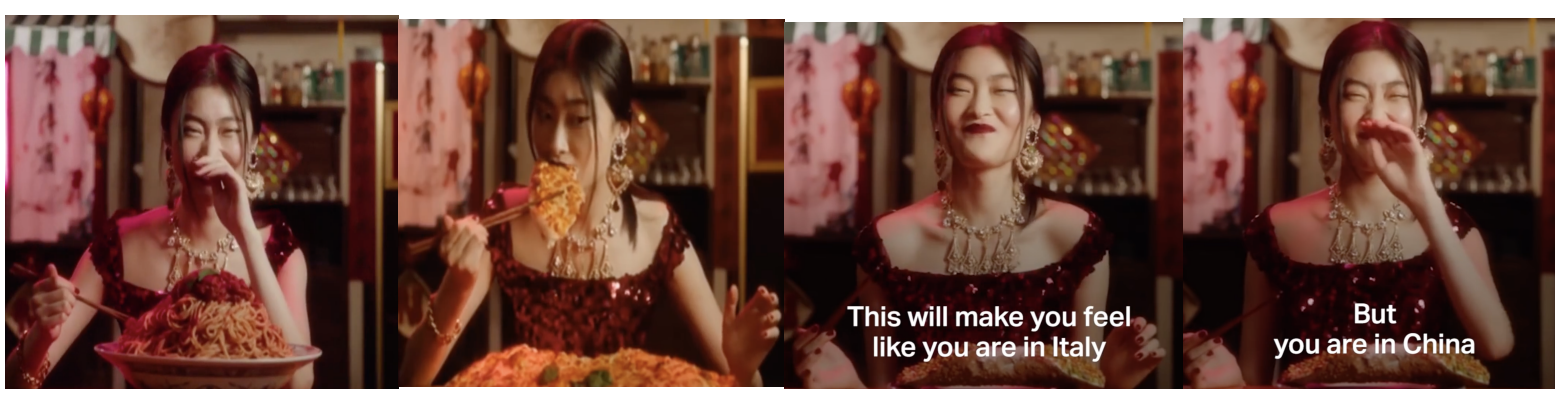

Figure 2. The $D \& G$ campaign on the Chinese market

Many Chinese people felt insulted by the ads, claiming that they were racist and based on the white West's orientalist perception of Chinese culture since they featured a hyper-sexualised Chinese woman against a background of exotic, kitschy imagery (Zang 2018). Dolce and Gabbana were forced to apologise publicly with a video message. ${ }^{5}$ They remarked on the need to reconsider the way they approach cultural differences, but they insisted they did not intentionally target Chinese people and culture.

Hence, it is interesting to analyse how this example of failed taboo humour was conceived by its creators and perceived by different receivers, especially in terms of potential offensiveness and (in)appropriateness. Clearly, all three commercials can be considered as instances of hyperdetermined humour because such humour is activated by many sources: the subtitles and voice-over, the model's exaggerated gestures and facial expressions, the Italian food and the Chinese setting, the chopsticks and the traditional Chinese music in the background. The whole scene triggers Script Oppositions such as "Italy/China", "Italian food/Chinese food" and even "cutlery/chopsticks". These references and oppositions are not offensive per se, yet the combination of linguistic and non-linguistic signs makes them come

4 All three D\&G commercials can be easily retrieved from the internet, e.g. on YouTube at: https://www.youtube.com/watch?v=TBFC5isQuYA (accessed: 21.04.2020).

${ }^{5} \mathrm{D} \& \mathrm{G}$ 's apology is available at: https://www.youtube.com/watch?v=7Ih621TKicg (accessed: 26.04.2020). 
across as inappropriate and disrespectful to Chinese culture. In particular, the cultural incongruity is conveyed by the girl's (unsuccessful) attempt to eat Italian food with chopsticks, which intertextually and metonymically seem to activate stereotyped references about the target culture. The advertised product (i.e. the D\&G clothing), which purports to resolve this incongruity (enjoying Italian lifestyle and food, despite not being Italian), instead brings the framing connotations of the incongruous combination to the fore. It is therefore likely that the individual awareness of many Chinese (and non-Chinese) people has led them to activate Script Oppositions such as "aptitude/ineptitude", "white/Asian race" and "appropriate/inappropriate", as Zang (2018) also suggests. Hence, the Target is not only the girl in the video but all Chinese people, their traditions, lifestyle, etc.

Conversely, D\&G (and their advertising team) probably considered these commercials amusing, aiming to playfully target not only the girl in the video but also Italian and Chinese cultural differences regarding food, etc. Nevertheless, the indirect references in these commercials seem to become an outlet for the two Italian designers' sense of superiority and mockery (Ermida 2008; Hill 2005). This broader target seems to overrule the potentially playful orientation of the ad, thus going beyond that threshold of taboo acceptance in advertising and becoming counterproductive (Sabri 2012: 418). Clearly, social norms and values play a fundamental role in the positive or negative attitude that people have towards taboo humour.

The two examples discussed so far demonstrate how intertextuality and (taboo) humour in advertising (or any type or public communication) would rather be handled carefully. What is more, they may often backfire, resulting in the potential buyers turning against the company or the brand itself. Two more examples will help further confirm this point. They rely on references to eroticism and sex, which are very common in advertising. Indeed, research in marketing has demonstrated that appealing to intrinsically hedonistic needs, such as sexual instincts and appetites, is likely to enhance consumers' motivation, opportunities and ability to process brand information in an advertisement (MacInnis et al. 1991: 35). As Freitas (2008: 127) also explains, "[t]he deliberate resource to some kinds of taboo such as eroticism or even bawdy humour makes the ads more memorable and capable of interacting with the viewers' imagination and fantasies". Like humour, sex is culture-bound and Biswas et al.'s (1992) analysis of humour and sex appeal in advertising has demonstrated that the French and Americans do make different uses of these phenomena. By contrast, the ad shown in Figure (3) is an interesting example that exploits sexist humour via its verbal text and image.

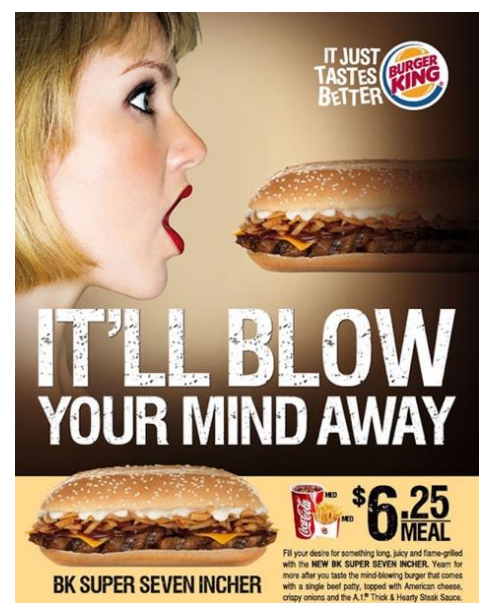

Figure 3. The 2009 Burger King's "It'll blow your mind away" ad. Source: https://www.reddit.com/r/AdFans/comments/5s914j/burger_king_ad_for_the_bk_super_seven _incher_itll/ 
This advert was launched in 2009 in Singapore by Burger King, an American global chain of fast food hamburger restaurants founded in 1954 in Miami, Florida. As can be seen, the billboard shows a girl facing a large seven-inch hamburger. Since the standard size of a sandwich is six inches, the short copy (verbal text; Simpson et al. 2019) in the advert "It'll blow your mind away" appears to work on two levels. On the one hand, the (non-offensive) idiomatic expression is used to express surprise at the "BK super seven incher". On the other hand, the homonymic reference exploits the vulgar (and potentially offensive) idiomatic expression that defines oral sex (i.e. to give someone a blow job). Clearly, the wordplay is linguistically activated by the verb blow and is central to the humorous incongruity the ad implies. Truly enough, the text is likely to activate the double entendre between the offensive and inoffensive idioms. However, it is the matching of the verbal text and the image that underscores the idea of oral sex, thus making it an instance of hyperdetermined humour. In particular, in the image, the sandwich roll is metaphorically associated with an oversized penis that is placed just in front of a wide-eyed girl with an open, red-lipsticked mouth. The girl's expression seems to suggest shock or surprise at the size of the sandwich, but the indirect intertextual reference is to the size of the penis. The incongruity breaks the frame of expectations regarding food and recast it in the sexual domain, thus resulting in a potentially humorous effect. This ad intertextually evokes Script Oppositions such as "a woman eating a sandwich/a woman performing oral sex" and "obscene/non-obscene". Strictly speaking, the Target is the girl in the picture.

The sexual innuendo in this advert was immediately criticised as distasteful and repulsive. As suggested in the examples discussed above, it is likely that the audience also transferred the disparaging humour targeting the girl in the picture to women at large, since the ad also seems to give rise to further oppositions, such as “men's domination/women's oppression". Some men may also find this advert inappropriate as it seems to depict them as 'perverts', thus also making them targets. Since this advert activates several targets, each of them may be considered simply amusing to some people but offensive to others. Indeed, those who probably felt offended vehemently spoke out against the advert. The corporation's spokesperson tried to respond to the customers' ire by saying that

[t]his print ad is running to support a limited time promotion in the Singapore market and is not running in the U.S. or any other markets. The campaign is supported by the franchisee in Singapore and has generated positive consumer sales around this limited time product offer in that market.

(Miller 2009)

This comment seems to suggest that people in Singapore did not perceive the ad to be offensive, but such claims are still hard to prove. Like in the case of H\&M, the company tried to address the fact that the ad was not meant to go circulate outside the local market, but such a stance is difficult to support in the case of a multinational corporation such as Burger King.

The last example I would like to discuss here plays again on oral sex, although this taboo topic is used to advertise oral care products. The campaign was launched in 2018 by Brushbox, a London-based toothbrush subscription service. The advert appeared in the form of a beermat and was included in a "welcome pack" given to students at the University of Sussex (Figure 4). 


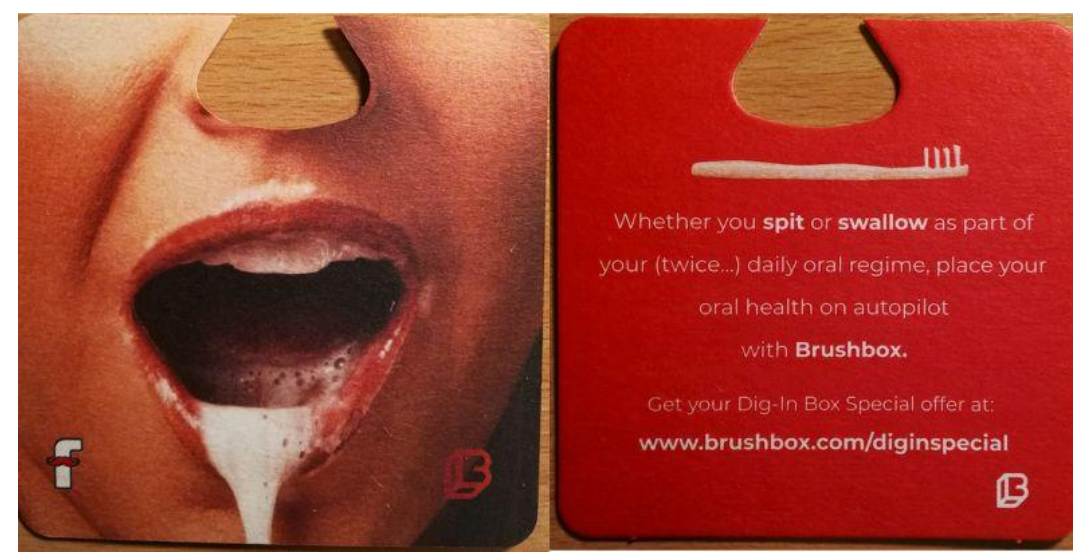

Figure 4. Brushbox beermat. Source: https://www.independent.co.uk/life-style/women/beermats-university-of-sussex-students-sexist-brushbox-dental-care-a8547226.html

One side of the beermat displays nothing but a picture of a person's mouth ${ }^{6}$ from which white fluid is dripping. On the other side, the receiver can read a long copy text which explains the importance of daily oral care. As they read the text, receivers revise their previous reading of the image and resolve the incongruity by interpreting the image as someone who is brushing their teeth and spitting out a mix of water and toothpaste. Nevertheless, the implied reference to oral sex in the image probably remains salient for many adult viewers and the words spit and swallow in bold in the verbal text further reinforce it. Like in the other cases, the hyperdetermined humour of this example derives from the simultaneous exploitation of the verbal and visual texts and their related intertextual sources. The double entendre in this advert triggers multiple Script Oppositions, including "oral sex/brushing teeth" and "obscene/nonobscene", but it is also likely to refer to the "men's domination/women's oppression" opposition also suggested in example (3). The offense seems to derive from the Targets that are activated. Strictly speaking, the target is the person in the picture, but it potentially extends to all those who perform oral sex, be they men or women. However, whether or not the potential humour in this ad is taken as an offense, very much depends on its individual reading (see footnote 6). There may be people who associate themselves with the targeted group (regardless of whether they perform oral sex or not) who may get offended. Vice versa, there may be people who perform oral sex and might find this ad amusing. Again, the potential humour in this ad and its allusions to (oral) sex are socially sanctioned (Bell 2015: 150) and may be accepted in private or informal settings or even anonymous contexts. Further research in this direction is certainly welcome as it may yield interesting results in terms of the appreciation of taboo humour. Like other ads, this advert sparked backlash among students, thus forcing the University of Sussex and Brushbox to issue an apology (Barr 2018). Once again, consumers' activism is what motivated the company's attempt to distance itself from the taboo humour in the ad. It has been demonstrated that negative publicity can still have positive effects on brand awareness, especially when the brand or product is not very well known and established (Berger et al. 2010). Example (4) may corroborate this claim since Brushbox was probably virtually unknown outside (or even across) the UK before this beermat came out. However, whether such notoriety persists or was short-lived is up to the marketers to assess.

\footnotetext{
${ }^{6}$ I asked some friends to look at this ad and it was interesting to note that most of them identified the person in the picture as a woman. However, one man claimed that he thought it was a man. Consequently, he said that the image was disturbing because the idea of a man performing oral sex, rather than a woman, was off-putting.
} 


\section{Concluding remarks}

The examples presented in this study have attempted to offer a glimpse on the functions and implications of taboo humour and intertextuality in advertising. The fact that this study relies on the examination of a small number of cases may certainly be seen as a limitation. However, as mentioned earlier, they have been selected because they share some common features. Firstly, they all hinge upon the intertextual exploitation of taboo stereotypes, idiomatic expressions and images that evoke a series of multilayered Script Oppositions and multiple Targets of disparagement within the same pool of buyers, or receivers. Hence, they can all be categorised as instances of hyperdetermined humour (Attardo 2001; Tsakona 2009). Secondly, all these cases of taboo humour in advertising have proved to be unsuccessful due to some customers' negative reactions and/or the community's active participation in the debate the ads sparked.

As Freitas (2008: 199) rightly remarks, "[a]part from the factual information they present - which is often the least part of it - ads convey important messages as to the way people view their roles in society". It is therefore not surprising that humour is of interest not only for scholars in business and marketing, but also in linguistics, sociology, etc. Investigating the use of (humorous) taboo topics in advertising further adds to the fascination of this phenomenon, as it is very likely to stir up controversy. As noted in the examples debated here, they have fostered discontent among the targeted and non-targeted clientele and fomented boycotting campaigns. This has also had social and economic implications for the brands. All the companies agreed to withdraw their ads and apologised publicly.

Although it may be argued that the potential offensiveness of these ads partially served their goals by making them trending topics on the internet, part of this success resulted in the receivers shaming the brand and its products. All in all, seeking social involvement via advertising is to some extent unpredictable and may have a boomerang effect, which results in the potential buyers turning against the company or brand itself. Unsurprisingly, advertisers prefer to exploit covert taboo references. This may be a way of avoiding taking full responsibility for what is being implied. As shown earlier, while offering their apologies, all the companies remarked that their intent was not to offend anyone, let alone their prospective customers. If any offence was caused, it was unintentional. However, "accidental intertextuality" seems untenable (Hale 2018: 511), especially when using taboo humour in advertising. In the $\mathrm{H} \& \mathrm{M}$ ad, the matching of the verbal reference with a black boy has unassailably triggered all the negative racist associations described above. The same applies to the idiom and the image of the girl facing a big sandwich in the Burger King ad, which indirectly refers to oral sex and, for some people, to sexism.

All in all, these adverts have proved promoters' and marketers' lack of understanding of the socio-cultural (or global) context within which advertising travels nowadays. In their apology, Dolce and Gabbana remarked on their willingness to better comprehend the culture their campaigns seek to address. Both BK and H\&M tried to justify themselves by claiming that their ads were to be limited to local markets. However, they seem to overlook the fact that in both cases they opted to exploit English idioms for their verbal texts. English is presently the lingua franca and the very concept of localisation is currently being challenged by the fact that many adverts are launched, easily retrieved and commented on the internet (and social media such as Instagram, Twitter, and Facebook), as all the examples above show.

This analysis could certainly be expanded to include local contexts and sectors, which may contribute to a better understanding of the social and cultural implications of the phenomenon of hyperdetermined humour in ads. For example, further research could concentrate on the cross-cultural use and appreciation of humour by looking at instances of translated adverts (cf. Fuentes Luque \& Valdés, forthcoming). In addition, the linguistic and 
cultural reasons for the failure of cross-cultural communication via advertising certainly deserve further investigation. It would be of enormous interest to verify the empirical effectiveness, or lack thereof, of taboo humour in advertising, as well as its workings from a linguistic standpoint.

\section{References}

Allen, G. (2000). Intertextuality. London: Routledge.

Attardo, S. (2001). Humorous Texts: A Semantic and Pragmatic Analysis. Berlin: Mouton de Gruyter.

Attardo, S. (1997). 'The semantic foundations of cognitive theories of humour'. Humour: International Journal of Humour Research 7 (1), pp. 395-420.

Attardo, S. (1994). Linguistic Theories of Humour. Berlin: Mouton de Gruyter.

Bakhtin, M. M. \& Volosinov V. N. (1986). Marxism and the Philosophy of Language (translated by L. Matejka \& I. R. Titunik). Cambridge: Harvard University Press.

Barr, S. (2018). 'Beer masts given to University of Sussex freshers condemned as "sexist"', The Independent, 29.9. Retrieved March 29, 2020 from https://www.independent.co.uk/life-style/women/beer-mats-university-of-sussex-studentssexist-brushbox-dental-care-a8547226.html.

Beard, F. K. (2008). 'Advertising and audience offense: The role of intentional humour'. Journal of Marketing Communications 14 (1), pp. 1-17.

Bell, N. (2015). We Are Not Amused: Failed Humour in Interaction. Berlin: Mouton de Gruyter.

Berger, A. A. (2015 [2000]). Ads, Fads, and Consumer Culture. Advertising's Impact on American Character and Society, 5th ed. Lanham: Rowman \& Littlefield.

Berger, J., Sorensen, A. T. \& Rasmussen, S. J. (2010). 'Positive effects of negative publicity: When negative reviews increase sales'. Marketing Science 29 (5), pp. 815-827.

Bernstein, D. (1974). Creative Advertising. London, Longman.

Biswas, A., Olsen, J. E. \& Carlet, V. (1992). 'A comparison of print advertisements from the United States and France'. Journal of Advertising 21 (4), pp. 73-81.

Boxman-Shabtai, L. \& Shifman, L. (2014). 'Evasive targets: Deciphering polysemy in mediated humour'. Journal of Communication 64 (5), pp. 977-988.

Catanescu, C. \& Tom, G. (2001). 'Types of humour in television and magazine advertising'. Review of Business 22 (1), pp. 92-96.

Chovanec, J. \& Tsakona, V. (2018). 'Investigating the dynamics of humour', in Tsakona, V. \& Chovanec, J. (eds.), Creating and Negotiating Humour in Everyday Interactions, Amsterdam: John Benjamins, pp. 1-26.

Dore, M. (2010). 'Manipulation of humorous culture-specific allusions in AVT'. In Harding, S.-A. \& Elimam, A. (eds.), CTIS Occasional Papers 4, Manchester: University of Manchester, pp. 5-28.

Dore, M. (2018). 'Controversial humour in advertising: Social and cultural implications' in Maon, F., Lindgreen, A., Vanhamme, J., Angell, R. J. \& Memery, J. (eds.), Not All Claps and Cheers: Humour in Business and Society Relationships, London: Routledge, pp. 132145.

Dore, M. (2019). Humour in Audiovisual Translation. Theories and Applications. London: Routledge.

Ermida, I. (2008). The Language of Comic Narratives: Humour Construction in Short Stories. Berlin: Mouton de Gruyter. 
Flaherty, K. E., Weinberger, M. G. \& Gulas, C. S. (2004). 'The impact of perceived humour, product type, and humour style in radio advertising'. Journal of Current Issues and Research in Advertising 26 (1), pp. 25-36.

Forceville, C. (2007). 'Mutlimodal metaphor in ten Dutch TV commercials'. The Public Journal of Semiotics 1 (1), pp. 15-34.

Freitas, E. S. L. (2008). Taboo in Advertising. Amsterdam: John Benjamins.

Freitas, E. S. L. (2016). 'Crude and taboo humour in television advertising: An analysis of commercials for consumer goods', in Bucaria, C. \& Barra, L. (eds.), Taboo Comedy, Television and Controversial Humour, London: Palgrave Macmillan, pp. 173-190.

Fuentes-Luque, A. \& Valdés, C. (forthcoming). 'Selling our souls for a laugh: Translated humour in advertising', in Dore, M. (ed.), Humour Translation in the Age of Multimedia, New York: Routledge.

Gérin, A. (2013). 'A second look at laughter: Humour in visual arts'. Humour: International Journal of Humour Research 26 (1), pp. 155-176.

Gulas, C. S. \& Weinberger, M. G. (2006). Humour in Advertising: A Comprehensive Analysis. New York: M. E. Sharpe.

Hale, A. (2018). 'There is an after-life (for jokes, anyway): The potential for, and appeal of, "immortality” in humour'. Humour: International Journal of Humour Research 31(3), pp. 507-538.

Hatzithomas, L., Boutsouki, C. \& Zotos, Y. (2016). 'The role of economic conditions on humour generation and attitude towards humorous TV commercials'. Humour: International Journal of Humour Research 29 (4), pp. 483-505.

Hempelmann, C. \& Miller, T. (2017). 'Puns: Taxonomies and phonology', in: Attardo, S. (ed.), The Routledge Handbook of Language and Humour, London: Routledge, pp. 95108.

Hill, J. H. (2005). 'Intertextuality as source and evidence for indirect indexical meanings'. Journal of Linguistic Anthropology 15 (1), pp. 113-124.

Hlynka, A., Knupfer, N. N. (1997). 'A thinking person's comedy: A study of intertextuality in "Cheers", in Griffin, R. E., Hunter, J. M., Schiffman, C. B., Gibbs, W. J. (eds.), Proceedings of VisionQuest: Journeys toward Visual Literacy. Selected Readings from the Annual Conference of the International Visual Literacy Association (28th, Cheyenne, Wyoming, October, 1996), pp. 401-410.

Kristeva, J. (1980). Desire in Language: A Semiotic Approach to Literature and Art (translated by L.S. Roudiez). Oxford: Blackwell.

Kuipers, G. (2009). 'Humour styles and symbolic boundaries'. Journal of Literary Theory 3 (2), pp. 219-240.

Laineste, L. \& Voolaid, P. (2016). 'Laughing across borders: Intertextuality of internet memes'. The European Journal of Humour Research 4 (4), pp. 26-49.

MacInnis, D. J., Moorman, C. \& Jaworski, B. J. (1991). 'Enhancing and measuring consumers' motivation, opportunity, and ability to process brand information from ads'. Journal of Marketing 55 (4), pp. 32-53.

Manteli, V. (2011). 'Humour and... Stalin in a National Theatre of Greece postmodern production', in Tsakona, V. \& Popa, D. E. (eds.), Studies in Political Humour: In Between Political Critique and Public Entertainment, Amsterdam: John Benjamins, pp. 243-270.

Miller, R. J. (2009). 'Critics cringe at ad for Burger King's latest sandwich'. Fox News, 30.6. Retrieved April, 13, 2020 from https://www.foxnews.com/story/critics-cringe-at-ad-forburger-kings-latest-sandwich.

Montgomery, M., Durant, A., Fabb, N., Furniss, T. \& Mills, S. (2007). Ways of Reading. 3rd ed. London: Routledge. 
Norrick, N. R. (1989). 'Intertextuality in humour'. Humour: International Journal of Humour Research 2 (2), pp. 117-139.

Norrick, N. R. (1993). Conversational Joking: Humour in Everyday Talk. Bloomington: Indiana University Press.

Raskin, V. (1985). Semantic Mechanisms of Humour. Dordrecht: D. Reidel.

Reuters (2008). 'Absolut vodka pulls ad showing California in Mexico'. 08.04. Retrieved April 24, 2020 from http://www.reuters.com/article/us-mexico-absolutidUSN0729018920080409.

Sabri, O. (2012). 'Taboo advertising: Can humour help to attract attention and enhance recall?' Journal of Marketing Theory and Practice 20 (4), pp. 407-422.

Saussure, F. de (1974). Course in General Linguistics. London: Fontana.

Simpson, P., Mayr, A. \& Statham, S. (2019). Language and Power: A Resource Book for Students, 2nd ed. London: Routledge.

Speck, P. S. (1991). 'The humorous message taxonomy: A framework for the study of humorous ads'. Current Issues \& Research in Advertising 13 (1), pp. 1-44.

Stack, L. (2018). 'H\&M Apologizes for 'Monkey' Image Featuring Black Child'. The New York Times 08/01. Retrieved April 19, 2020 from https://www.nytimes.com/2018/01/08/business/hm-monkey.html.

Tsakona, V. (2009). 'Language and image interaction in cartoons: Towards a multimodal theory of humour'. Journal of Pragmatics 41, pp. 1171-1188.

Tsakona, V. (2018). 'Intertextuality and/in political jokes'. Lingua 203, pp. 1-15.

Werner, W. (2004). 'On political cartoons and social studies textbooks: visual analogies, intertextuality, and cultural memory'. Canadian Social Studies 38 (2). Retrieved April 19, $2020 \mathrm{from} \mathrm{https://canadian-social-studies-journal.educ.ualberta.ca/content/articles-2000-}$ 2010\#ARpolitical_cartoons_ss_textbooks202.

Zhang, M. M. (2018). 'Dolce \& Gabbana's cancelled chopsticks advert shows us orientalism is finally being taken seriously as a form of racism'. Independent 24/11. Retrieved April 26, 2020 from https://www.independent.co.uk/voices/dolce-and-gabbana-racist-advertchinese-woman-d-g-orientalism-video-a8649741.html. 